\title{
Febrile Neutropenia in Transplant Recipients
}

\author{
Lior Nesher and Kenneth V. I. Rolston
}

\section{Introduction}

Hematopoietic transplantation has been used to treat many disorders including neoplastic, hematologic, immunologic, and metabolic diseases. Currently, most hematopoietic transplants are performed for the treatment of hematologic malignancies [1]. Hematopoietic cells for transplantation can be collected from various sources including bone marrow, peripheral blood, and umbilical cord blood. Autologous transplants utilize the patient's own cells, whereas allogeneic transplants utilize cells obtained from a different individual. Syngeneic transplants are between genetically identical twins. Conditioning therapy given prior to hematopoietic transplantation can be myeloablative or non-myeloablative (i.e., reduced intensity) and produces significant neutropenia (absolute neutrophil count $[\mathrm{ANC}] \leq 500$ cells $/ \mathrm{mm}^{3}$ ), which is the most common predisposing factor for the development of bacterial and fungal infections during the pre-engraftment phase. Neutropenia is more prolonged in recipients of myeloablative allogeneic transplants than in recipients of non-myeloablative or autologous transplants. Thus, the frequency and severity of infection in allogeneic transplant recipients are greater than in other transplant subgroups [2-6]. Some patients with hematologic malignancies may have normal or even elevated ANCs but may be at increased risk for infection due to defects in neutrophil function (qualitative neutropenia). These defects include significant reduction in phagocytosis, decreased bac-

\section{Nesher}

Infectious Disease Institute, Faculty of Health Sciences,

Ben-Gurion University of the Negev, Beer Sheba, Israel

Soroka University Medical Center affiliated with Faculty of Health Sciences Ben-Gurion University of the Negev, Infectious Disease Institute, Beer Sheba, Israel

e-mail: nesherke@bgu.ac.il

K. V. I. Rolston $(\bowtie)$

Department of Infectious Diseases, Infection Control \& Employee Health, The University of Texas MD Anderson Cancer Center,

Houston, TX, USA

e-mail: krolston@mdanderson.org tericidal and fungicidal activity, decreased production of superoxide anions, and defects in granulocyte locomotion. Myeloablative conditioning regimens also inflict substantial damage to mucosal barriers causing mucositis of the mouth and gastrointestinal tract, resulting in increased risk of infections arising from these sites [7, 8]. Early recognition and aggressive management of infection is critical for the overall survival of hematopoietic transplant recipients, and delays in the administration of appropriate anti-infective therapy are associated with poorer outcomes [9]. Unfortunately, signs and symptoms commonly associated with infection may be blunted in these highly immunosuppressed patients. Often the only manifestation of infection during an episode of neutropenia is fever. This condition is commonly referred to as "febrile neutropenia." The widely accepted definition of febrile neutropenia is an oral temperature of $\geq 38.3^{\circ} \mathrm{C}$, or two consecutive readings of $>38{ }^{\circ} \mathrm{C}$ during a $2 \mathrm{~h}$ period, and an absolute neutrophil count of $<500 / \mathrm{mm}^{3}$ [10]. It has been estimated that approximately $80 \%$ of allogeneic transplant recipients and a smaller but substantial proportion of allogeneic transplant recipients will develop febrile neutropenia. It is important to keep in mind that some neutropenic patients, especially those receiving corticosteroids, may not mount an adequate inflammatory response and may be afebrile or even hypothermic while developing or harboring a significant infection. A high index of suspicion and close monitoring during periods of increased risk is essential in such patients.

The administration of prompt, broad-spectrum, empiric, antimicrobial therapy has become the standard of care for most febrile neutropenic patients including transplant recipients [10]. The general principles of such therapy for both adult and pediatric patients have been published in guidelines issued by various learned societies [10-13]. Specific treatment regimens for individual patients generally take into consideration local epidemiologic trends and local susceptibility/resistance patterns since geographic and institutional differences do occur. Periodic surveillance studied to monitor changes in the epidemiology of infections and in susceptibility and resistance patterns are important especially in 
institutions that perform large numbers of hematopoietic transplants.

\section{Types of Febrile Episodes}

Although fever is the most frequent and occasionally the only manifestation of infection in neutropenic patients, a substantial number of patients remain febrile without a specific infection being documented. A specific causative pathogen, most often bacterial or fungal, is identified in only $20-25 \%$ of febrile neutropenic episodes, referred to as episodes of microbiologically documented infection [14]. An additional $20-25 \%$ of patients will have an identifiable site of infection (e.g., pneumonia, cellulitis, enterocolitis) but will have negative cultures (Fig. 9.1). This may be due to various reasons such as the use of antimicrobial prophylaxis which may render cultures negative or substantially delay the time to positivity or a blunted inflammatory response which can result in paucity of specimens (e.g., sputum) to culture. These episodes are referred to as clinically documented infections. Approximately 40-50\% of febrile neutropenic patients have neither clinical evidence of infection nor positive microbiological documentation of one, which are referred to as episodes of unexplained fever. The majority of these episode are probably caused by undetected infections as most of them respond to empiric antimicrobial therapy. A small proportion of patients with fever and neutropenia have noninfectious causes of fever such as drug fever or tumor fever. This is not surprising since fever is induced by cytokine release which is not limited to infections. All febrile neutropenic patients should undergo a thorough evaluation to detect infection before the possibility of a noninfectious etiology is entertained. Most microbiologically documented infections are monomicrobial (i.e., caused by one organism) with Gram-positive bacteria being predominant $[10,15]$. However, polymicrobial infections are

Fig. 9.1 Types and distribution of febrile episodes in neutropenic patients being documented with increasing frequency at many transplant centers and may account for up to $25 \%$ of bacterial infections [16]. Recent data show that $\sim 10-15 \%$ of bacteremias in neutropenic patients are polymicrobial [17]. Infections involving deep tissue sites such as pneumonia, enterocolitis, and perirectal infections are often polymicrobial [16, 18]. Most polymicrobial infections are caused by multiple bacterial species although bacterial and fungal, bacterial and viral, or fungal and viral infections may be present at the same time. These infections are generally associated with greater morbidity and mortality than monomicrobial infections.

\section{Sites of Infection}

The most common sites of infection documented in neutropenic hematopoietic transplant recipients are listed in Table 9.1. Infections of the respiratory tract occur most often followed by bloodstream infections (including central line-associated bloodstream infection, CLABSI), urinary tract infections, skin and skin structure infections (SSSIs), and infections originating from the oropharynx, the gastrointestinal tract, and the biliary tract [14]. Less frequent but clinically important sites include the central nervous system, the musculoskeletal system, and the end organs such as the spleen and liver. The frequency of bloodstream infection (BSI) varies from center to center and also on the type of transplant, generally being more frequent in allogeneic transplant recipients $[19,20]$. Recent data indicate that the incidence of at least one episode of BSI is around $21 \%$ with an attributable mortality of $3 \%$ [21]. Approximately $25 \%$ of patients with profound neutropenia lasting $>10-12$ days will develop lung infiltrates. These often do not respond to broad-spectrum antimicrobial therapy and establishing a specific diagnosis in such patients remains a significant challenge [22]. Data regarding other sites of infection are not as robust as those describing BSIs.

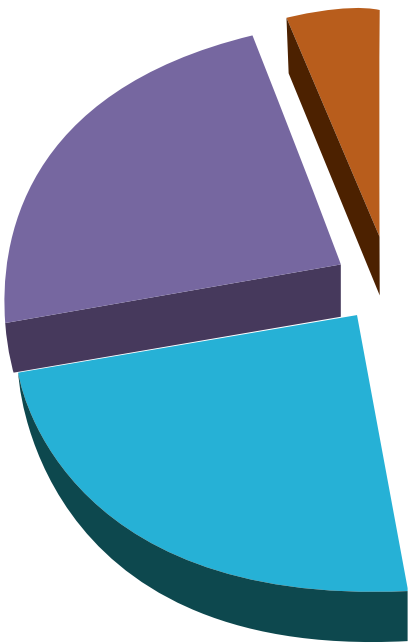

unexplained fever 45 - 50\%

- clinically documented infections 20 $25 \%$ (predominantly respiratory and SSIs)

- microbiologically documented infections $20-25 \%$ (predominantly bacterial and fungal)

non infectious causes of fever $<5 \%$ (predominantly drug and tumor fever) 
Table 9.1 Common sites of infection in febrile neutropenic patients

\begin{tabular}{|l|l|}
\hline Site of infection & Frequency range \\
\hline Respiratory tract $^{\mathrm{b}}$ & $35-40 \%$ \\
\hline Bloodstream $^{\mathrm{c}}$ & $15-35 \%$ \\
\hline Urinary tract $^{\mathrm{S}}$ & $5-15 \%$ \\
\hline Skin and skin structure & $5-10 \%$ \\
\hline Gastrointestinal tract $^{\mathrm{e}}$ & $5-10 \%$ \\
\hline Other sites $^{\mathrm{f}}$ & $5-10 \%$ \\
\hline
\end{tabular}

These data were extracted from various epidemiologic surveys conducted at the University of Texas MD Anderson Cancer Center between 2004 and 2014

${ }^{a}$ Approximately $15-20 \%$ of patients will have multiple sites of infection (i.e., bacteremia + pneumonia). These are not always caused by the same organisms

'Includes the para nasal sinuses, the upper respiratory tract, the lungs, and infections such as empyema

'Includes primary and catheter-related bacteremia

${ }^{\mathrm{d} I n c l u d e s}$ infections at surgical sites, bone marrow biopsy sites, and radiation fields

'Includes infections arising from the oral cavity, esophagitis, appendicitis, neutropenic enterocolitis, cholangitis, and perirectal infections

${ }_{\mathrm{f}}^{\mathrm{f}}$ entral nervous system, bone, joint, etc.

Most microbiologically documented infections arise from the patient's endogenous microflora, with only a small proportion being acquired from exogenous sources and/or environmental exposure. It is therefore often possible to anticipate the potential etiology of an infection and provide appropriate empiric coverage based on the site where the infection originated. For example, most infections with a cutaneous origin are caused by Staphylococcus species and other organisms that colonize the skin (Bacillus spp., Corynebacterium spp., Candida spp.) [23]. Patients with severe oral mucositis and/or poor periodontal status are more likely to have infections caused by viridans group streptococci (VGS) and Stomatococcus mucilaginosus [24-26]. In patients with significant lower intestinal mucositis, enterococcal and Gram-negative bacillary infections occur more often. Bacterial infections generally occur during the initial stages of a neutropenic episode, while fungal infections arise more frequently in patients with prolonged ( $\geq 7$ days) neutropenia. The widespread use of long-term central venous catheters in transplant recipients has had an impact on the frequency and spectrum of infection. The ability of certain organisms (notably coagulase-negative staphylococci (CoNS), Staphylococcus aureus, and Candida spp.) to produce and get embedded in biofilm, and the poor penetration of many antimicrobial agents into biofilm, makes catheter-related infections difficult to eradicate without removal of the offending catheter [27]. Consequently many transplant centers perform routine weekly blood cultures from central venous catheters in an attempt to detect colonization/infection early $[28,29]$. This practice, however, has not been shown to accurately predict the development of CLABSI and may lead to unnecessary interventions [30]. The most common organisms isolated from CLABSI are CoNS. Other organisms include S. aureus, Bacillus spp., Corynebacterium spp.,
Pseudomonas aeruginosa, Enterobacteriaceae, Enterococcus spp., Acinetobacter spp., Stenotrophomonas maltophilia, and Candida spp. Despite the widespread use of catheters, the infection rate seldom exceeds $15 \%$ or more than two episodes per 1000 catheter days [31].

\section{Bacterial Infections}

Several recent epidemiologic surveys conducted in pediatric and adult hematopoietic transplant recipients have documented the predominance of Gram-positive organisms over Gram-negative bacilli [32-34]. Some of the reasons for this predominance include (1) the widespread use of central venous catheters, (2) the frequent use of intensive chemotherapeutic regimens that produce significant oral mucositis, and (3) the use of antibacterial prophylaxis (generally with a fluoroquinolone) directed primarily against enteric Gram-negative bacilli. Fluoroquinolone prophylaxis has in fact been show to increase the frequency of Grampositive infections especially with organisms such as VGS that are often resistant to them [35]. The proportion of Gram-positive infections has been reported to be as high as $70-80 \%$ at some centers. Many reports, however, include data only on BSI caused by single organisms (monomicrobial BSI) and either exclude or provide very little details regarding infections at other sites and on polymicrobial infections [36]. These reports provide an overestimate of Gram-positive infections since the majority of bacteremias, particularly CLABSI, are indeed caused by Gram-positive organisms that inhabit the skin. As mentioned previously, BSIs account for only $20-25 \%$ of microbiologically documented infections. Infections at most other sites such as lungs, intestinal tract, urinary tract, and biliary tract have a predominance of Gram-negative pathogens. Additionally, $\sim 60-80 \%$ of polymicrobial infections have a Gram-negative component, and $\sim 30-35 \%$ are caused exclusively by multiple Gram-negative species [16, 18]. Therefore, when all sites of infection, not just BSI and monomicrobial as well as polymicrobial infections are pooled together, the apparent predominance of Gram-positive organisms seems less striking, with Gram-negative organisms being isolated almost as frequently [37]. Indeed, some institutions are beginning to report a resurgence in the frequency of Gram-negative pathogens even in patients with BSI [32]. The main reason for this appears to be the discontinuation of fluoroquinolone prophylaxis at some institutions since this practice has resulted in the emergence of fluoroquinolone-resistant and even multidrug-resistant organisms [32]. For reasons that remain unclear anaerobes are seldom isolated from neutropenic patients, although it is customary to provide anaerobic coverage especially for infections arising from or involving the intestinal tract. Real-time knowledge of local epidemio- 
logical patterns is critical, and empiric regimens need to be based on such information. Consequently, transplant centers are encouraged to perform periodic surveillance studies in order to keep abreast of epidemiologic changes. The organisms causing the majority if bacterial infections in neutropenic hematopoietic transplant recipients are listed in Tables 9.2 and 9.3 .

Table 9.2 The spectrum of Gram-positive organisms isolated from febrile neutropenic patients

\begin{tabular}{|l|c|}
\hline Organism & \% Frequency \\
\hline CoNS $^{\mathrm{a}}$ & $20-50$ \\
\hline Staphylococcus aureus $^{\mathrm{a}}$ & $10-30$ \\
Enterococcus species $^{\mathrm{b}}$ & $10-20$ \\
\hline VGS $^{\mathrm{c}}$ & $5-25$ \\
Micrococcus species $^{\mathrm{a}}$ & $2-8$ \\
\hline Corynebacterium species & $2-5$ \\
$\beta$ hemolytic streptococci $^{\mathrm{d}}$ & $4-6$ \\
\hline Bacillus species & $4-6$ \\
\hline Aerococcus species & $<3$, respectively \\
\hline Streptococcus pneumoniae & \\
\hline Stomatococcus mucilaginosus & \\
\hline Lactobacillus species & \\
\hline Leuconostoc species & \\
\hline Pediococcus species &
\end{tabular}

These data were extracted from various epidemiologic surveys conducted at the University of Texas MD Anderson Cancer Center between 2004 and 2014

${ }^{a}$ CoNS - coagulase-negative staphylococci - approximately $7 \%$ of CoNS were S. lugdunensis. $>95 \%$ of CoNS and $>65 \%$ of S. aureus isolates were methicillin-resistant

${ }^{\mathrm{b}}$ Approximately $18 \%$ of Enterococcus species were vancomycinresistant enterococci (VRE)

${ }^{c}$ VGS - viridans group streptococci - the most common species were $S$. mitis, $S$. sanguis, and S. salivarius

${ }^{\mathrm{d} I n c l u d e d ~ g r o u p s ~ A, ~ B, ~ C, ~ G, ~ a n d ~ F ~}$

Table 9.3 Spectrum of Gram-negative organisms isolated from febrile neutropenic patients

\begin{tabular}{|c|c|}
\hline Organism & $\%$ Frequency \\
\hline Escherichia coli $^{\mathrm{a}}$ & $20-45$ \\
\hline Klebsiella species $^{\mathrm{b}}$ & 10-20 \\
\hline Other Enterobacteriaceae ${ }^{\mathrm{c}}$ & $15-20$ \\
\hline Pseudomonas aeruginosa ${ }^{\mathrm{d}}$ & $18-24$ \\
\hline Stenotrophomonas maltophilia ${ }^{\mathrm{d}}$ & $2-5$ \\
\hline Acinetobacter species ${ }^{d}$ & $<3$ \\
\hline Other NFGNB ${ }^{\mathrm{e}}$ & $<3$ \\
\hline \multicolumn{2}{|c|}{ 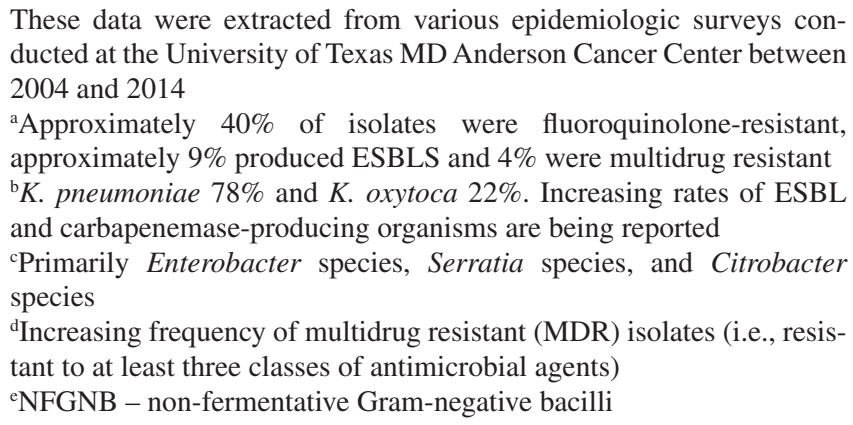 } \\
\hline
\end{tabular}

\section{Gram-Positive Organisms}

Coagulase-negative staphylococci are isolated most often with the most common species being Staphylococcus epidermidis, S. hominis, and S. haemolyticus. These organisms are of low virulence and seldom cause life-threatening infections even in severely neutropenic patients. CLABSI are the most common infections caused by CoNS. These can often be treated with antimicrobial agents alone, although catheter removal may be required if the infection recurs [38]. The one exception is S. lugdunensis, which more closely resembles $S$. aureus in virulence [39-41]. Many experts recommend that these organisms should not be considered to be harmless commensals and infections caused by them should be managed like those caused by $S$. aureus. Other Gram-positive organisms that colonize the human skin and cause infections in neutropenic patients include Bacillus spp., Corynebacterium spp., and Micrococcus spp. Like CoNS, these organisms cause CLABSI most often, although serious infections such as endophthalmitis, endocarditis, septic arthritis, and pneumonia develop occasionally. As mentioned, S. aureus are more virulent than other staphylococci and are associated with substantial morbidity and mortality. Patients with $S$. aureus bacteremia should be evaluated with infections such as endocarditis and deep-seated abscesses [42]. Unlike CoNS catheter removal is almost always necessary in $S$. aureus CLABSI [43]. Of concern are the increasing rates of methicillin resistance among $S$. aureus (MRSA) isolates worldwide. Although MRSA rates as low as $10 \%$ are still reported occasionally, many institutions are reporting MRSA rates in the range of $55-60 \%$, making them more common than methicillin-susceptible isolates. Some MRSA isolates have developed tolerance (MBC $\geq 32$ times the MIC) or reduced susceptibility to vancomycin (referred to as the MIC creep), thereby reducing the therapeutic impact of this agent, which until recently has been considered to be the agent of choice for the treatment of Gram-positive infections in neutropenic patients [44, 45]. Alternative agents are being recommended for infections caused by such organisms [46].

Alpha-hemolytic streptococci or VGS are major components of the human oral microflora. Patients particularly prone to VGS infections are recipients of high-intensity chemotherapy with agents such as cytosine arabinoside which induces severe mucosal damage and facilitates translocation of these organisms into the bloodstream. Other predisposing factors include the use of fluoroquinolone prophylaxis and the use of antacids and histamine type-2 (H2) antagonists. Although not recommended by most authorities, vancomycin-based prophylaxis in the peri-transplant period has been used by some, in order to reduce the frequency of VGS bacteremia [47]. This practice 
requires close monitoring of patients for the development of resistant organisms such as VRE and/or staphylococcal isolates with reduced susceptibility or resistance to vancomycin. It should only be considered in institutions where the frequency of infections caused by VGS is very high. Also of concern is the possibility that this practice might lead to the development of reduced susceptibility to other agents (daptomycin, dalbavancin). Some investigators believe that mucositis, which generally occurs at the nadir of neutropenia, is the primary predisposing factor for the development of infection in this setting, and have coined the phrase "febrile mucositis." Additionally, periodontal inflammation including gingivitis, periodontitis increases the possibility of VGS bacteremia [24, 48]. The most common manifestation of VGS infection is bacteremia. Approximately $5-10 \%$ of patients may develop disseminated infection, the so-called streptococcal toxic shock syndrome in which the mortality rate is in the range of $40-50 \%$ despite appropriate therapy [49]. Streptococcus mitis, S. sanguis, and S. salivarius are the species isolated most often from patients with VGS bacteremia. Of increasing concern are reports that up to $20-60 \%$ of VGS isolates are non-susceptible or overtly resistant to penicillin [50]. All isolates are currently susceptible to vancomycin, although occasional tolerance to this agent has been described [45]. They are also susceptible to newer-generation quinolones such as moxifloxacin and agents such as linezolid, daptomycin, telavancin, and dalbavancin, although clinical experience with these agents is limited [51-53]. The use of antibiotic combinations may be warranted, especially against organisms with high MICs or tolerance to vancomycin.

The enterococci reside mainly in the lower intestinal tract. They are seldom primary pathogens but are isolated most often following prolonged therapy with broad-spectrum agents such as the carbapenems. The most common manifestations include BSI and urinary tract infections. Enterococci are also often isolated from polymicrobial infections such as neutropenic enterocolitis and perirectal infections. The increased and prolonged use of vancomycin in neutropenic patients was in part responsible for the emergence of vancomycin-resistant enterococci (VRE) globally, and currently, 15-20\% of all enterococcal isolates in the United States are VRE. Fecal colonization with VRE in hematopoietic transplant recipients is not uncommon, and approximately $15-40 \%$ of colonized patients will develop BSI or other serious infections [54-58]. Consequently, some experts recommend the preemptive use of agents with activity against VRE when patients with fecal colonization develop febrile neutropenia. Fecal decolonization has been attempted, but most attempts have been unsuccessful. Therefore, antimicrobial stewardship and infection control measures to limit the emergence and spread of VRE are extremely important.

\section{Gram-Negative Organisms}

The gastrointestinal tract serves as an important source of infection in neutropenic patients, with the predominant pathogens being enteric Gram-negative bacilli. The use of antimicrobial prophylaxis in high-risk neutropenic patients including hematopoietic transplant recipients led to a decline in the frequency and, to some extent, the morbidity and mortality associated with documented Gram-negative infections. This practice also led to the emergence of resistance among Escherichia coli and other Gram-negative species [59-61]. Therefore, many institutions are re-evaluating this practice, and some institutions have even discontinued fluoroquinolone prophylaxis in neutropenic patients [32]. Many institutions conduct surveillance studies in high-risk patients looking for fecal colonization with VRE, Pseudomonas aeruginosa, and other resistant organisms such as extended-spectrum beta-lactamase (ESBL) producers and carbapenem-resistant Enterobacteriaceae (CRE), since positive surveillance cultures often predict the development of infections during subsequent episodes of neutropenia [55, 62, 63]. This information is useful in picking appropriate empiric regimens when colonized patients develop febrile neutropenia, as well as in antimicrobial stewardship efforts if surveillance cultures are negative. ESBL-producing organisms are being reported with increasing frequency [64]. Carbapenemaseproducing Gram-negative bacteria (Klebsiella pneumonia carbapenemase, KPC; New Delhi metallo-beta-lactamase 1, NDM-1; non-metallo-beta-lactamase producers) have emerged over the past few years and are spreading across the globe $[65,66]$. Gram-negative infections are usually associated with greater morbidity and mortality than Gram-positive infections. Many epidemiological studies have shown that E. coli, Klebsiella species (K. pneumoniae and K. oxytoca), and $P$. aeruginosa remain the three primary Gram-negative pathogens in neutropenic patients causing 45-60\% of such infections [36, 37]. Other Enterobacteriaceae (Citrobacter spp., Enterobacter spp., Proteus spp., Serratia spp.) are less common, although institutional differences do exist [67, 68]. Nationwide outbreaks of Serratia marcescens bacteremia due to contaminated prefilled heparin and saline syringes have been reported [69, 70]. Despite the overall decline in the frequency of Gram-negative infections, the proportion of infections caused by non-fermentative Gram-negative bacilli (NFGNB) such as $P$. aeruginosa, non-aeruginosa pseudomonads, Stenotrophomonas maltophilia, and Acinetobacter species has increased $[67,71]$. Collectively, NFGNB now cause $\sim 40 \%$ of all Gram-negative infections, a proportion that has steadily increased over the past two decades. $P$. aeruginosa is the most important and most frequently isolated NFGNB and causes between $15 \%$ and $20 \%$ of Gram-negative infections [72]. Bacteremia and pneumonia are the two most common manifestations, although infections at various other 
sites are not uncommon. It is also the most common Gramnegative organism isolated from polymicrobial infections [16]. These organisms develop resistance to antimicrobial agents using multiple mechanisms and often acquire resistance to several classes of agents (multidrug resistance, MDR) and are difficult to treat and eradicate. Combination therapy is often necessary. Prolonged use of fluoroquinolones and carbapenems has been identified as risk factor for the development of resistance [73-75]. Consequently, many antimicrobial stewardship efforts focus on curtailing or minimizing the use of these agents. Colonization/infection with $S$. maltophilia is also being reported more often especially in patients with hematologic malignancies and hematopoietic transplant recipients $[76,77]$. The shift from trimethoprim/sulfamethoxazole (which has potent activity against $S$. maltophilia) to fluoroquinolones (which do not) as the preferred agents for antimicrobial prophylaxis in neutropenic patients may account for this increase. These organisms are almost always multidrug resistant, and as is the case with $P$. aeruginosa, combination therapy (trimethoprim/sulfamethoxazole + minocycline or tigecycline) is frequently necessary [77, 78]. Other infrequent but important NFGNB include Acinetobacter spp., Achromobacter and Alcaligenes spp., and non-aeruginosa Pseudomonas species such as $P$. putida and $P$. fluorescens. Many outbreaks caused by these organisms have been traced to contaminated dialysis fluid, de-ionized water, mechanical ventilators, and chlorhexidine solution. Many of these organisms are also multidrug resistant.

\section{Anaerobic Infections}

Anaerobic infections are seldom documented in febrile neutropenic patients, with the overall range of positive blood cultures being 0-5\% [79]. The most common sites of infection are the intestinal tract (neutropenic enterocolitis, perirectal infections, abdominal/pelvic abscesses), complicated skin and skin structure infections, biliary tract infections, and respiratory infections $[14,80]$. It is customary to provide anaerobic coverage to treat these infections even if anaerobes have not been isolated. The presence of significant oral or intestinal mucositis increases the risk of anaerobic infections. Purulence, which is the hallmark of anaerobic infections in immunocompetent patients, is often absent in patients with neutropenia. The organisms isolated most often include Peptostreptococcus spp., Fusobacterium nucleatum, Bacteroides spp., Prevotella spp., and Clostridium spp. Due to the frequent and prolonged use of broad-spectrum antimicrobial agents, Clostridium difficile-associated diarrhea is not infrequent in patients with neutropenia [81]. Approximately $13 \%$ of hematopoietic transplant recipients develop $C$. difficile infection mainly in the 1 st month post- transplantation [82]. Colonization with toxigenic strains of $C$. difficile has been shown to be predictive for the development of $C$. difficile-associated diarrhea in hematopoietic transplant recipients [83, 84]. Response to treatment may be lower and relapses or recurrent infections may be higher in this setting.

The spectrum of bacterial infection in neutropenic patients continues to change with significant geographic and institutional differences being commonplace. In institutions wherein fluoroquinolone prophylaxis is still in use, Grampositive pathogens predominate, whereas in institutions that have suspended or discontinued the use of fluoroquinolone prophylaxis, Gram-negative pathogens are more common. Resistance patterns also vary from region to region and, indeed, sometimes within the same region or institution. Resistant organisms are uncommon in Scandinavian countries. VRE appears to be more common in the United States than in Europe. The frequency of ESBL-producing, carbapenemase-producing, and MDR Gram-negative organisms appears to be increasing worldwide. Consequently, generating real-time local epidemiologic and susceptibility/ resistance data is important.

\section{Fungal Infections}

Bacterial infections predominate during the initial 7-10 days of neutropenia. With more prolonged neutropenia, fungal infections begin to develop. Infections caused by Candida spp. and Aspergillus spp. are documented most often although many opportunistic fungi are pathogenic in this setting (Table 9.4). Invasive candidiasis was the most common fungal infection in neutropenic patients prior to the development of agents such as fluconazole, with $C$. albicans being the predominant species. With the routine usage of antifungal prophylaxis in high-risk patients including hematopoietic transplant recipients, the frequency of invasive candidiasis has been substantially reduced with manifestations like esophagitis and chronic systemic or hepatosplenic candidiasis becoming almost of historic interest. Currently candidemia, most often catheter-related, is the most common manifestation of invasive candidiasis. There has also been a shift in the epidemiology of candidiasis, in part related to the usage of agents such as fluconazole, with the emergence of Candida species other than $C$. albicans such as C. glabrata, C. tropicalis, $C$. parapsilosis, C. krusei, C. auris as frequent pathogens in this setting $[85,86]$. Regional differences have been documented with a preponderance of different species in different institutions. These differences may be due to divergent use of antifungal prophylaxis and/or geographic diversity. As with bacterial infections, local epidemiologic and susceptibility/resistance data should be used to guide empiric 
Table 9.4 The spectrum of fungal and viral infections in neutropenic patients

\begin{tabular}{l} 
Fungal pathogens (yeast) $-8-24 \%$ of blood stream infections in \\
patients with hematological malignancy \\
Candida albicans \\
Other candida species ${ }^{\mathrm{a}}$ \\
\hline Trichosporon beigelii \\
Geotrichum capitatum \\
Malassezia furfur \\
Hansenula anomala \\
\hline Streptomyces cerevisiae \\
\hline Fungal pathogens (molds) $-2-28 \%$ of patients with hematological \\
malignancy \\
\hline Aspergillus fumigatus \\
\hline Other Aspergillus species \\
The Zygomycetes \\
\hline Fusarium species \\
\hline Scedosporium species \\
Viral pathogens \\
\hline Herpes simplex viruses (reactivation) \\
Community respiratory viruses \\
\hline
\end{tabular}

These data were extracted from various epidemiologic surveys conducted at the University of Texas MD Anderson Cancer Center between 2004 and 2014

${ }^{a}$ Includes C. glabrata, C. tropicalis, C. krusei, C. auris, and C. parapsilosis 'Includes A. flavus, A. niger, A. terreus, and A. oryzae

${ }^{\mathrm{c}}$ Rhizopus, Mucor, Rhizomucor, Absidia, and Cunninghamella are the most common human pathogens

${ }^{\mathrm{d} I n c l u d e s ~ i n f l u e n z a ~ A ~ a n d ~ B, ~ p a r a i n f l u e n z a ~ v i r u s e s, ~ r e s p i r a t o r y ~ s y n c y-~}$ tial virus (RSV), human metapneumovirus, corona viruses, rhinoviruses, and bocavirus. Infection may not necessarily be more common in neutropenic patients but tends to be more severe

and targeted antifungal therapy. Other yeasts occasionally encountered in this setting include Trichosporon beigelii, Hansenula anomala, Geotrichum capitatum, Malassezia furfur, and Streptomyces cerevisiae.

Invasive mold infections are the most common lifethreatening infections in patients with neutropenia that last longer than 2 weeks [87]. The vast majority of these infections are caused by Aspergillus species with A. fumigatus being the predominant species. Other species of Aspergillus have emerged as significant pathogens as well, including A. flavus, A. terreus, A. niger, and A. oryzae (Table 9.4). The most common site of involvement is the lung, resulting in invasive pulmonary aspergillosis (IPA). Other frequent sites of involvement include the paranasal sinuses and the central nervous system. Fungemia is rarely documented. Although still relatively uncommon, mucormycosis has emerged as an increasingly important infection in neutropenic patients in the last 15-20 years [88]. The most common organisms causing this infection are Mucor spp., Rhizopus spp., Rhizomucor spp., Cunninghamella spp., and Absidia spp. The increasing frequency of mucormycosis has in part been attributed to the use of voriconazole, due to its lack of activity against these organisms [89-91]. Like aspergillosis, common sites of infection include the paranasal sinuses, the rhino-orbital area, the lungs, and the central nervous system [92]. Other uncommon but important molds that cause infection in this setting include Fusarium spp. and Scedosporium spp. Unlike most other molds, fungemia is a common manifestation of fusariosis and may occur in up to $50 \%$ of patients [93]. Necrotic cutaneous lesions are also relatively common. The incidence of Scedosporium infection appears to be increasing in recent years. This increase may also be related to the fact that these organisms are resistant to many commonly used antifungal agents [94].

\section{Viral Infections}

Viral infections, especially those caused by human herpes viruses, are common in high-risk patients with neutropenia including hematopoietic cell transplant recipients. Most are effectively prevented with antiviral prophylaxis and/or preemptive therapy. Most herpes simplex virus (HSV 1 and HSV 2) infections in adults are due to reactivation of latent infections in seropositive patients. The likelihood of viral reactivation depends on the intensity of the chemotherapeutic/conditioning regimen. Reactivation occurs in two-thirds of patients undergoing induction chemotherapy for acute myelogenous leukemia and in recipients of hematopoietic transplants in the absence of antiviral prophylaxis [95, 96]. Ulcerations of the oral and esophageal mucosa, ulcers, or vesicles on the lips, genitalia, skin, or perianal areas are the most common manifestations. The HSVs can cause numerous syndromes including encephalitis, meningitis, myelitis, esophagitis, hepatitis, ocular disease, pneumonia, and erythema multiforme. Reactivation, or less commonly, primary acquisition of other human herpes viruses such as Cytomegalovirus, Epstein-Barr virus, and human herpes virus 6 can also occur, albeit, seen mostly during late transplant period [97-100].

Infections caused by respiratory viruses may not necessarily occur more frequently in neutropenic patients, but their manifestations tend to be more severe in this setting [101]. This may even impact the decision to proceed with hematopoietic cell transplantation, and several guidelines recommend delaying transplantation in patients with pretransplant upper respiratory tract infections [101-103]. These pathogens include the influenza viruses (influenza A and B), respiratory syncytial virus (RSV), parainfluenza viruses, adenovirus, and metapneumovirus [104]. The risk for infection by these organisms tends to coincide with respiratory virus outbreaks in the general population. The severity of infection and specifically the rate of progression from upper respiratory tract disease to lower respiratory tract disease such as pneumonia depend on the level, duration, and type of immunosuppression [104-107]. 


\section{Polymicrobial Infections}

As previously mentioned, approximately $25-30 \%$ of microbiologically documented infections are polymicrobial. In the past polymicrobial infections have been ignored or underappreciated and underreported [16]. Of late, greater attention is being paid to such infections. In general, they are associated with greater morbidity and mortality than monomicrobial infections. This may be because polymicrobial infections frequently involve deep tissues (pneumonia, empyema, neutropenic enterocolitis, perirectal infections) where penetration of antimicrobial agents might be subtherapeutic and large areas of under perfused or necrotic tissue may be present. Recent studies also show that $\sim 15 \%$ of bacteremic infections including CLABSI are polymicrobial [17]. Grampositive organisms, predominantly staphylococci and enterococci, are isolated from up to $40 \%$ to $50 \%$ of polymicrobial infections, whereas Gram-negative organisms are isolated from $\sim 80 \%$ of polymicrobial infections with $P$. aeruginosa and $E$. coli being isolated most often. Approximately onethird are caused by multiple Gram-negative species e.g., $E$. coli \& $P$. aeruginosa [18]. Occasionally bacterial and fungal, bacterial and viral, fungal and viral, or multiple fungal infections may coexist.

It is important to remember that neutropenia is often superimposed on other immunological defects such as impaired cellular or humoral immunity both as a result of the underlying malignancy and/or its treatment prior to transplantation. If such deficits are present in addition to neutropenia, the spectrum of infection widens considerably as these deficits are associated with their own unique set of pathogens.

\section{Management of Febrile Neutropenia}

The principles of managing episodes of febrile neutropenia have been developed and refined over several decades [10, 108-110]. Many societies including the Infectious Diseases Society of America (IDSA), the National Comprehensive Cancer Network (NCCN), the American Society of Clinical Oncology (ASCO), and the European Society of Medical Oncology (ESMO) have published evidence-based guidelines that provide current information regarding the management (including prevention) of these episodes $[10,11,13$, $111,112]$. All febrile neutropenic patients should undergo a quick but thorough initial evaluation and should receive prompt, broad-spectrum, empiric, antibiotic therapy based on current local epidemiologic and susceptibility/resistance patterns. Several options are available for initial empiric therapy including (1) monotherapy with a broad-spectrum antipseudomonal agent or (2) various combination regimens. Depending on the patients' risk group, such therapy may be administered in the hospital or in an outpatient setting and may be parenteral or oral. Close monitoring for response or progression of infection, the development of complications or drug-related adverse effects, and the development of superinfections is critical. Modification of the initial regimen may be required in up to $30 \%$ of patients depending on the risk group, nature and site of infection, and the development of a superinfection (including a suspected or documented fungal infection). Removal of infected catheters and other medical hardware may be necessary. Surgical intervention may be indicated in specific settings (e.g., perirectal infection/abscess). The overall duration of therapy depends on several factors such as the patients risk group, nature and site of infection, and resolution or persistence of neutropenia. These principles are discussed below.

\section{Initial Evaluation}

A detailed history should be taken including the nature and intensity of chemotherapy, prior antibiotic usage (prophylactic and therapeutic), use of corticosteroids or other immunosuppressive agents, recent surgical procedures including placement of medical hardware, allergies, and recent travel or potential exposure to sick contacts. A history of past infection and/or colonization with resistant organisms will also have an impact on the selection of an appropriate empiric antimicrobial regimen. A thorough physical examination is mandatory and often reveals important sites of infection including cutaneous lesions such as ecthyma gangrenosum, cellulitis, and perirectal infection/abscesses. The examination of catheter insertion sites, external auditory meatus, nares and nasal septum, and the oropharynx may also often reveal foci of infection. Additionally, it is important to remember that some neutropenic patients, especially those receiving corticosteroids, may be afebrile. Others may just feel unwell and may even hypothermic. Such patients may harbor serious infections such as Gram-negative septicemia.

Laboratory evaluation should include a complete blood count (CBC) with differential leucocyte count and platelet count, measurement of serum creatinine blood urea nitrogen (BUN) to assess renal function, and measurement of serum electrolytes, total bilirubin, and hepatic transaminase enzymes. At least two sets of blood cultures should be obtained (one from a peripheral vein and the other from a central venous catheter, if present). Each lumen of multilumen catheters should be cultured separately [113]. Culture specimens from other sites (urine, wounds, sputum if available) should be obtained as indicated. Chest radiographs are not recommended routinely but should be obtained in patients with respiratory symptoms or signs [114].

The initial evaluation of a febrile neutropenic patient should also include risk assessment as this guides the choice 
of the empiric antibiotic regimen (combination vs monotherapy), the route of administration (parenteral vs oral), the setting in which therapy is administered (hospital vs outpatient), and the duration of therapy. The most commonly used risk assessment system in adults is the MASCC risk index [115]. High-risk patients have a MASCC risk score of $<21$ and should be admitted to the hospital for empiric therapy and close monitoring. Low-risk patients have a MASCC risk score of $\geq 21$ and may be candidates for outpatient (oral or parenteral) therapy. Separate risk assessment tools are available for pediatric febrile neutropenic patients [116, 117].

\section{Empiric Therapy}

An algorithm for the management of febrile neutropenic patients is provided in Fig. 9.2. Once the initial evaluation and risk assessment have been completed, empiric antibiotic therapy should be administered without undue delay [10]. Lowrisk patients can be treated with oral or parenteral regimens (Table 9.5). These can be administered during a short period of hospitalization followed by outpatient therapy or treatment of the entire episode in the outpatient setting. Most oral regimens are fluoroquinolone-based combinations although fluoroquinolone monotherapy has also been shown to be safe and effective $[118,119]$. It is important to point out that hematopoietic cell transplant recipients (even those receiving non-myeloablative and/or autologous transplants) seldom fall into the low-risk category. Most hematopoietic transplant recipients with febrile neutropenia will either already be in the hospital or will require hospitalization for the administration of parenteral antibiotic therapy. Monotherapy with an antipseudomonal beta-lactam agent such as cefepime, a carbapenem such as meropenem or imipenem-cilastatin (but not ertapenem, as it is not active against $P$. aeruginosa), or piperacillin-tazobactam is recommended (Table 9.5). Other agents (aminoglycosides, fluoroquinolones, tigecycline, polymyxin-colistin, metronidazole) may be needed if antimicrobial resistance is suspected or documented or a specific pathogen such as an ESBL-producing or carbapenemaseproducing Gram-negative bacillus or an anaerobe is isolated. The initial use of agents such as vancomycin, daptomycin, or linezolid is discouraged except when prior colonization or infection with a resistant Gram-positive organism (MRSA, VRE) has been documented or a catheter-related infection is strongly suspected $[10,120]$. The empiric use of vancomycin has not been shown to reduce the overall mortality in patients with Gram-positive infections with the possible exception of infections caused by VGS. Additionally, one recent study has demonstrated that the empiric use of linezolid in febrile neu-

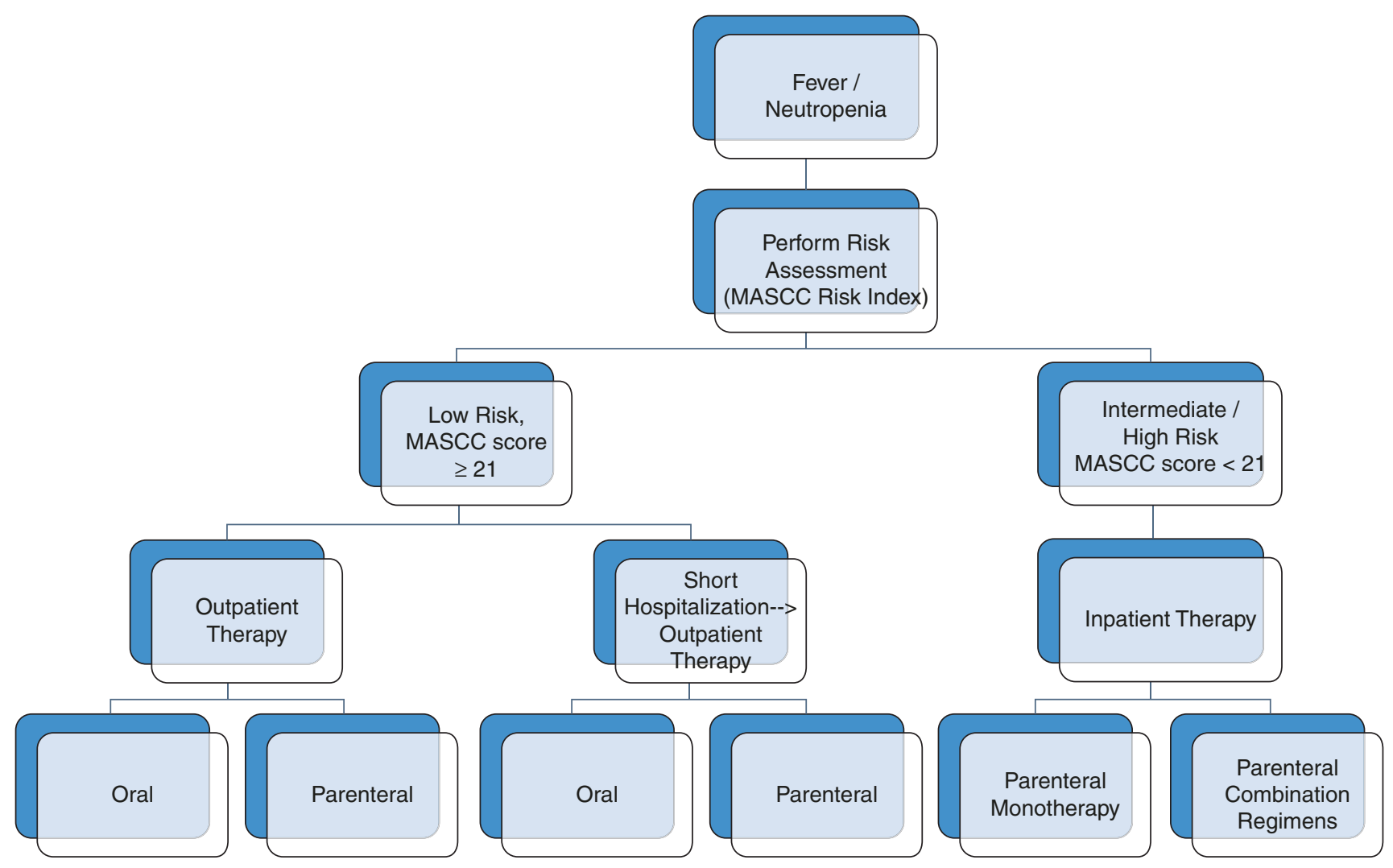

Fig. 9.2 Treatment algorithm for febrile neutropenic patients. Specific agents/regimens are listed in Table 9.5 
Table 9.5 Common antibiotic regimens used in febrile neutropenic patients

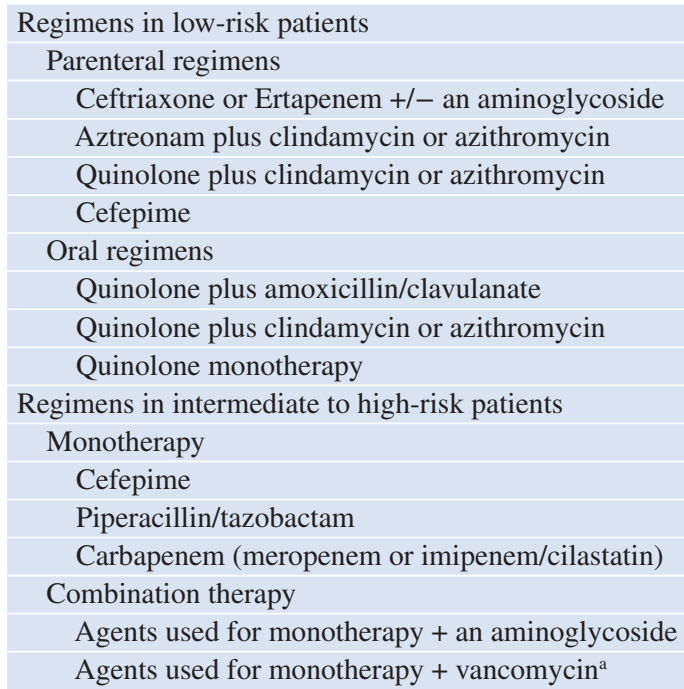

${ }^{a}$ Alternative agents such as daptomycin and linezolid are being used with increasing frequency although clinical data are limited

tropenic patients colonized with VRE had no impact on mortality as well [121]. Concern has also been raised about the development of linezolid resistance, which has already been reported with increased usage of this agent [122]. Empiric antifungal coverage should be instituted if patients remain febrile after 4-7 days.

\section{Duration of Therapy}

The duration of therapy continues to be vigorously debated. In patients with episodes of unexplained fever, therapy is generally continued until marrow recovery (ANC $>500$ cells/ $\mathrm{mm}^{3}$ for 2 consecutive days). Some experts recommend discontinuation of therapy if the patient has defervesced, even though marrow recovery as defined above has not yet occurred. It is recommended to place these patients on their initial prophylactic regimen until neutropenia resolves. In patients with microbiologically or clinically documented infections, the duration of therapy usually depends on the site of infection (cellulitis or UTI requiring a shorter duration than bacteremia or pneumonia) and the organism isolated. In patients with CLABSI caused by $S$. aureus, $P$. aeruginosa, Candida spp. or other fungi, or mycobacteria, catheter removal in addition to appropriate antimicrobial therapy is recommended [43].

Therapy is generally continued until marrow recovery or longer if clinically indicated. The ultimate decision as to when to stop therapy often needs to be individualized and may depend on numerous factors such as the patient's risk group, the presence of a documented infection, and/or the persistence of neutropenia.
Table 9.6 Strategies for Antimicrobial stewardship program

\section{General strategies}

Determine and monitor local epidemiology and resistance patterns Develop multidisciplinary antimicrobial stewardship team (MAST)

Antimicrobial usage strategies

Limit antibacterial prophylaxis

Encourage targeted/specific therapy

Consider formulary restriction and/or pre-authorization

Create local guidelines and clinical pathways

Consider antimicrobial heterogeneity

Consider de-escalation (streamlining) of empiric regimen

Dose optimization

Parenteral to oral transition

Optimize duration of therapy

Other strategies

Prospective audits of antimicrobial usage with feedback to prescribers

Educational activities (grand rounds, in-services)

Strict adherence to infection control policies

Adapted from [123, 125-127]

\section{Infection Control and Antimicrobial Stewardship}

Hand hygiene, cutaneous antisepsis, and maximum sterile barrier precautions are recommended for all procedures such as $\mathrm{CVC}$ insertions and bone marrow biopsies. Strict adherence to infection control practices and policies is essential in minimizing the spread of infections and controlling outbreaks, especially those caused by resistant organisms in the hospital and in other healthcare settings. Antimicrobial stewardship is essential especially since the frequent use of antimicrobial therapy in these high-risk patients creates selection pressures leading to the development of resistance. The various strategies for antimicrobial stewardship are listed in Table 9.6 and include a multidisciplinary antibiotic stewardship team (MAST), institutional pathways/guidelines, formulary restrictions or pre-approval requirements for certain agents, and de-escalation or streamlining of therapy when appropriate and feasible [123, 124]. Antimicrobial stewardship programs have been successfully instituted at several institutions [125-127]. Although currently the primary focus of these programs has been stewardship of antibacterial agents, it is anticipated that these programs will soon expand to include antifungal and antiviral agents as well.

\section{References}

1. Jones R, Shpall E, Champlin R. In Holland-Frei editor. Hematopoietic cell transplantation. 9th ed. Hoboken: John Wiley and sons. 2017, p 831-41.

2. Almyroudis NG, Fuller A, Jakubowski A, et al. Pre- and postengraftment bloodstream infection rates and associated mortality 
in allogeneic hematopoietic stem cell transplant recipients. Transp Infect Dis. 2005;7(1):11-7.

3. Sorror ML, Storer BE, Maloney DG, Sandmaier BM, Martin PJ, Storb R. Outcomes after allogeneic hematopoietic cell transplantation with nonmyeloablative or myeloablative conditioning regimens for treatment of lymphoma and chronic lymphocytic leukemia. Blood. 2008;111(1):446-52.

4. Celebi H, Akan H, Akçağlayan E, Ustün C, Arat M. Febrile neutropenia in allogeneic and autologous peripheral blood stem cell transplantation and conventional chemotherapy for malignancies. Bone Marrow Transplant. 2000;26(2):211-4.

5. Gil L, Styczynski J, Komarnicki M. Infectious complication in 314 patients after high-dose therapy and autologous hematopoietic stem cell transplantation: risk factors analysis and outcome. Infection. 2007;35(6):421-7.

6. Zhang WX, Zhao QY, Huang HQ. Febrile neutropenic infection occurred in cancer patients undergoing autologous peripheral blood stem cell transplantation. Transplant Proc. 2015;47(2):523-7.

7. van der Velden WJ, Herbers AH, Netea MG, Blijlevens NM. Mucosal barrier injury, fever and infection in neutropenic patients with cancer: introducing the paradigm febrile mucositis. Br J Haematol. 2014;167(4):441-52.

8. Vera-Llonch M, Oster G, Ford CM, Lu J, Sonis S. Oral mucositis and outcomes of allogeneic hematopoietic stem-cell transplantation in patients with hematologic malignancies. Support Care Cancer. 2007;15(5):491-6.

9. Safdar A, Armstrong D. Infections in patients with hematologic neoplasms and hematopoietic stem cell transplantation: neutropenia, humoral, and splenic defects. Clin Infect Dis. 2011;53(8):798-806.

10. Freifeld AG, Bow EJ, Sepkowitz KA, et al. Clinical practice guideline for the use of antimicrobial agents in neutropenic patients with cancer: 2010 update by the infectious diseases society of America. Clin Infect Dis. 2011;52(4):e56-93.

11. Baden LR, Bensinger W, Angarone M, et al. Prevention and treatment of cancer-related infections. J Natl Compr Cancer Netw. 2012;10(11):1412-45.

12. Lehrnbecher T, Phillips R, Alexander S, et al. Guideline for the management of fever and neutropenia in children with cancer and/or undergoing hematopoietic stem-cell transplantation. J Clin Oncol. 2012;30(35):4427-38.

13. de Naurois J, Novitzky-Basso I, Gill MJ, et al. Management of febrile neutropenia: ESMO clinical practice guidelines. Ann Oncol. 2010;21(Suppl 5):v252-6.

14. Nesher L, Rolston KVI. The current spectrum of infection in cancer patients with chemotherapy related neutropenia. Infection. 2014;42(1):5-13.

15. Nesher L, Rolston KVI, Shah DP, et al. Fecal colonization and infection with Pseudomonas aeruginosa in recipients of allogeneic hematopoietic stem cell transplantation. Transpl Infect Dis. 2015;17(1):33-8.

16. Rolston KV, Bodey GP, Safdar A. Polymicrobial infection in patients with cancer: an underappreciated and underreported entity. Clin Infect Dis. 2007;45(2):228-33.

17. Klastersky J, Ameye L, Maertens J, et al. Bacteraemia in febrile neutropenic cancer patients. Int J Antimicrob Agents. 2007;30(Suppl 1):S51-9.

18. Elting LS, Bodey GP, Fainstein V. Polymicrobial septicemia in the cancer patient. Medicine (Baltimore). 1986;65(4):218-25.

19. Gudiol C, Garcia-Vidal C, Arnan M, et al. Etiology, clinical features and outcomes of pre-engraftment and post-engraftment bloodstream infection in hematopoietic SCT recipients. Bone Marrow Transplant. 2014;49(6):824-30.

20. Piñana JL, Montesinos P, Martino R, et al. Incidence, risk factors, and outcome of bacteremia following autologous hematopoietic stem cell transplantation in 720 adult patients. Ann Hematol. 2014;93(2):299-307.
21. Blennow O, Ljungman P, Sparrelid E, Mattsson J, Remberger $\mathrm{M}$. Incidence, risk factors, and outcome of bloodstream infections during the pre-engraftment phase in 521 allogeneic hematopoietic stem cell transplantations. Transpl Infect Dis. 2014;16(1):106-14.

22. Maschmeyer G, Carratalà J, Buchheidt D, et al. Diagnosis and antimicrobial therapy of lung infiltrates in febrile neutropenic patients (allogeneic SCT excluded): updated guidelines of the Infectious Diseases Working Party (AGIHO) of the German Society of Hematology and Medical Oncology (DGHO). Ann Oncol. 2015;26(1):21-33.

23. Rolston KV, Nesher L, Tarrand JT. Current microbiology of surgical site infections in patients with cancer: a retrospective review. Infect Dis Ther. 2014;3(2):245-56.

24. Raber-Durlacher JE, Laheij AM, Epstein JB, et al. Periodontal status and bacteremia with oral viridans streptococci and coagulase negative staphylococci in allogeneic hematopoietic stem cell transplantation recipients: a prospective observational study. Support Care Cancer. 2013;21(6):1621-7.

25. Blijlevens NM, Donnelly JP, de Pauw BE. Empirical therapy of febrile neutropenic patients with mucositis: challenge of risk-based therapy. Clin Microbiol Infect. 2001;7(Suppl 4):47-52.

26. Fanourgiakis P, Georgala A, Vekemans M, Daneau D, Heymans C, Aoun M. Bacteremia due to Stomatococcus mucilaginosus in neutropenic patients in the setting of a cancer institute. Clin Microbiol Infect. 2003;9(10):1068-72.

27. Singh R, Ray P, Das A, Sharma M. Penetration of antibiotics through Staphylococcus aureus and Staphylococcus epidermidis biofilms. J Antimicrob Chemother. 2010;65(9):1955-8.

28. Kanathezhath B, Shah A, Secola R, Hudes M, Feusner JH. The utility of routine surveillance blood cultures in asymptomatic hematopoietic stem cell transplant patients. J Pediatr Hematol Oncol. 2010;32(4):327-31.

29. Rigby H, Fernandez CV, Langley J, Mailman T, Crooks B, Higgins A. Routine surveillance for bloodstream infections in a pediatric hematopoietic stem cell transplant cohort: do patients benefit? Can J Infect Dis Med Microbiol. 2007;18(4):253-6.

30. Nesher L, Chemaly RF, Shah DP, Mulanovich VE, Hosing C, Rolston KVI. Utility of routine surveillance blood cultures in asymptomatic allogeneic hematopoietic stem cell transplant recipients with indwelling central venous catheters at a comprehensive cancer center. Am J Infect Control. 2014;42(10):1084-8.

31. Cecinati V, Brescia L, Tagliaferri L, Giordano P, Esposito S. Catheter-related infections in pediatric patients with cancer. Eur J Clin Microbiol Infect Dis. 2012;31(11):2869-77.

32. Montassier E, Batard E, Gastinne T, Potel G, de La Cochetière MF. Recent changes in bacteremia in patients with cancer: a systematic review of epidemiology and antibiotic resistance. Eur J Clin Microbiol Infect Dis. 2013;32(7):841-50.

33. Macesic N, Morrissey CO, Cheng AC, Spencer A, Peleg AY. Changing microbial epidemiology in hematopoietic stem cell transplant recipients: increasing resistance over a 9-year period. Transpl Infect Dis. 2014;16(6):887-96.

34. Miedema KG, Winter RH, Ammann RA, et al. Bacteria causing bacteremia in pediatric cancer patients presenting with febrile neutropenia - species distribution and susceptibility patterns. Support Care Cancer. 2013;21(9):2417-26.

35. Razonable RR, Litzow MR, Khaliq Y, Piper KE, Rouse MS, Patel R. Bacteremia due to viridans group Streptococci with diminished susceptibility to Levofloxacin among neutropenic patients receiving levofloxacin prophylaxis. Clin Infect Dis. 2002;34(11): 1469-74.

36. Wisplinghoff $\mathrm{H}$, Seifert $\mathrm{H}$, Wenzel RP, Edmond MB. Current trends in the epidemiology of nosocomial bloodstream infections in patients with hematological malignancies and solid neoplasms in hospitals in the United States. Clin Infect Dis. 2003;36(9):1103-10. Epub 2003 Apr 14. 
37. Yadegarynia D, Tarrand J, Raad I, Rolston K. Current spectrum of bacterial infections in patients with cancer. Clin Infect Dis. 2003;37(8):1144-5.

38. Raad I, Chaftari AM. Advances in prevention and management of central line-associated bloodstream infections in patients with cancer. Clin Infect Dis. 2014;59(Suppl 5):S340-3.

39. Giormezis N, Kolonitsiou F, Makri A, et al. Virulence factors among Staphylococcus lugdunensis are associated with infection sites and clonal spread. Eur J Clin Microbiol Infect Dis. 2015;34(4):773-8.

40. Kleiner E, Monk AB, Archer GL, Forbes BA. Clinical significance of Staphylococcus lugdunensis isolated from routine cultures. Clin Infect Dis. 2010;51(7):801-3.

41. Fadel HJ, Patel R, Vetter EA, Baddour LM. Clinical significance of a single Staphylococcus lugdunensis-positive blood culture. J Clin Microbiol. 2011;49(4):1697-9.

42. Mihu CN, Schaub J, Kesh S, et al. Risk factors for late Staphylococcus aureus bacteremia after allogeneic hematopoietic stem cell transplantation: a single-institution, nested case-controlled study. Biol Blood Marrow Transplant. 2008;14(12):1429-33.

43. O'Grady NP, Alexander M, Burns LA, et al. Guidelines for the prevention of intravascular catheter-related infections. Clin Infect Dis. 2011;52(9):e162-93.

44. Sakoulas G, Moise-Broder PA, Schentag J, Forrest A, Moellering RC, Eliopoulos GM. Relationship of MIC and bactericidal activity to efficacy of vancomycin for treatment of methicillinresistant Staphylococcus aureus bacteremia. J Clin Microbiol. 2004;42(6):2398-402.

45. Safdar A, Rolston KV. Vancomycin tolerance, a potential mechanism for refractory gram-positive bacteremia observational study in patients with cancer. Cancer. 2006;106(8):1815-20.

46. Liu C, Bayer A, Cosgrove SE, et al. Clinical practice guidelines by the infectious diseases society of America for the treatment of methicillin-resistant Staphylococcus aureus infections in adults and children. Clin Infect Dis. 2011;52(3):e18-55.

47. Seo SK, Xiao K, Huang YT, et al. Impact of peri-transplant vancomycin and fluoroquinolone administration on rates of bacteremia in allogeneic hematopoietic stem cell transplant (HSCT) recipients: a 12-year single institution study. J Infect. 2014;69(4):341-51.

48. Graber CJ, de Almeida KN, Atkinson JC, et al. Dental health and viridans streptococcal bacteremia in allogeneic hematopoietic stem cell transplant recipients. Bone Marrow Transplant. 2001;27(5):537-42.

49. Elting LS, Bodey GP, Keefe BH. Septicemia and shock syndrome due to viridans streptococci: a case-control study of predisposing factors. Clin Infect Dis. 1992;14(6):1201-7.

50. Han XY, Kamana M, Rolston KV. Viridans streptococci isolated by culture from blood of cancer patients: clinical and microbiologic analysis of 50 cases. J Clin Microbiol. 2006;44(1):160-5.

51. Rolston KV, Besece D, Lamp KC, Yoon M, McConnell SA, White P. Daptomycin use in neutropenic patients with documented grampositive infections. Support Care Cancer. 2014;22(1):7-14.

52. Rolston KVI, Wang W, Nesher L, Coyle E, Shelburne S, Prince RA. In vitro activity of telavancin compared with vancomycin and linezolid against gram-positive organisms isolated from cancer patients. J Antibiot. 2014;67(7):505-9.

53. Rolston KV, Frisbee-Hume S, LeBlanc B, Streeter H, Ho DH. In vitro antimicrobial activity of moxifloxacin compared to other quinolones against recent clinical bacterial isolates from hospitalized and community-based cancer patients. Diagn Microbiol Infect Dis. 2003;47(2):441-9.

54. Matar MJ, Tarrand J, Raad I, Rolston KV. Colonization and infection with vancomycin-resistant enterococcus among patients with cancer. Am J Infect Control. 2006;34(8):534-6.

55. Liss BJ, Vehreschild JJ, Cornely OA, et al. Intestinal colonisation and blood stream infections due to vancomycin-resistant enterococci (VRE) and extended-spectrum beta-lactamase-producing
Enterobacteriaceae (ESBLE) in patients with haematological and oncological malignancies. Infection. 2012;40(6):613-9.

56. Bossaer JB, Hall PD, Garrett-Mayer E. Incidence of vancomycinresistant enterococci (VRE) infection in high-risk febrile neutropenic patients colonized with VRE. Support Care Cancer. 2010;19(2):231-7.

57. Kang M, Xie Y, He C, et al. Molecular characteristics of vancomycin-resistant Enterococcus faecium from a tertiary care hospital in Chengdu, China: molecular characteristics of VRE in China. Eur J Clin Microbiol Infect Dis. 2014;33(6):933-9.

58. Kang Y, Vicente M, Parsad S, et al. Evaluation of risk factors for vancomycin-resistant enterococcus bacteremia among previously colonized hematopoietic stem cell transplant patients. Transpl Infect Dis. 2013;15(5):466-73.

59. Mihu CN, Rhomberg PR, Jones RN, Coyle E, Prince RA, Rolston KV. Escherichia coli resistance to quinolones at a comprehensive cancer center. Diagn Microbiol Infect Dis. 2010;67(3): 266-9.

60. Bhusal Y, Mihu CN, Tarrand JJ, Rolston KV. Incidence of fluoroquinolone-resistant and extended-spectrum $\beta$-lactamaseproducing Escherichia coli at a comprehensive cancer center in the United States. Chemotherapy. 2011;57(4):335-8.

61. Kern WV, Klose K, Jellen-Ritter AS, et al. Fluoroquinolone resistance of Escherichia coli at a cancer center: epidemiologic evolution and effects of discontinuing prophylactic fluoroquinolone use in neutropenic patients with leukemia. Eur J Clin Microbiol Infect Dis. 2005;24(2):111-8.

62. Rolston KV, Nesher L, Mulanovich V, Chemaly R. Intestinal colonisation and blood stream infections due to vancomycinresistant enterococci (VRE) and extended-spectrum betalactamase-producing enterobacteriaceae (ESBLE) in patients with haematological and oncological malignancies. Infection. 2013;41(5):1039-40.

63. Biehl LM, Schmidt-Hieber M, Liss B, Cornely OA, Vehreschild MJ. Colonization and infection with extended spectrum betalactamase producing Enterobacteriaceae in high-risk patients review of the literature from a clinical perspective. Crit Rev Microbiol. 2016;42(1):1-16.

64. Kim SH, Kwon JC, Choi SM, et al. Escherichia coli and Klebsiella pneumoniae bacteremia in patients with neutropenic fever: factors associated with extended-spectrum $\beta$-lactamase production and its impact on outcome. Ann Hematol. 2013;92(4):533-41.

65. Patel G, Bonomo RA. "Stormy waters ahead": global emergence of carbapenemases. Front Microbiol. 2013;4:48.

66. Pillai DR, McGeer A, Low DE. New Delhi metallo- $\beta$ lactamase-1 in Enterobacteriaceae: emerging resistance. CMAJ. 2011;183(1):59-64.

67. Rolston KV, Tarrand JJ. Pseudomonas aeruginosa - still a frequent pathogen in patients with cancer: 11-year experience at a comprehensive cancer center. Clin Infect Dis. 1999;29(2):463-4.

68. Safdar A, Rodriguez GH, Balakrishnan M, Tarrand JJ, Rolston $\mathrm{KV}$. Changing trends in etiology of bacteremia in patients with cancer. Eur J Clin Microbiol Infect Dis. 2006;25(8):522-6.

69. Chemaly RF, Rathod DB, Sikka MK, et al. Serratia marcescens bacteremia because of contaminated prefilled heparin and saline syringes: a multi-state report. Am J Infect Control. 2011;39(6):521-4.

70. Chemaly RF, Rathod DB, Raad II. A tertiary care cancer center experience of the 2007 outbreak of Serratia marcescens bloodstream infection due to prefilled syringes. Infect Control Hosp Epidemiol. 2009;30(12):1237-8.

71. Rolston KV, Kontoyiannis DP, Yadegarynia D, Raad II. Nonfermentative gram-negative bacilli in cancer patients: increasing frequency of infection and antimicrobial susceptibility of clinical isolates to fluoroquinolones. Diagn Microbiol Infect Dis. 2005;51(3):215-8. 
72. Hakki M, Limaye AP, Kim HW, Kirby KA, Corey L, Boeckh M. Invasive Pseudomonas aeruginosa infections: high rate of recurrence and mortality after hematopoietic cell transplantation. Bone Marrow Transplant. 2007;39(11):687-93.

73. Ohmagari N, Hanna H, Graviss L, et al. Risk factors for infections with multidrug-resistant Pseudomonas aeruginosa in patients with cancer. Cancer. 2005;104(1):205-12.

74. Aboufaycal H, Sader HS, Rolston K, et al. blaVIM-2 and blaVIM-7 carbapenemase-producing Pseudomonas aeruginosa isolates detected in a tertiary care medical center in the United States: report from the MYSTIC program. J Clin Microbiol. 2007;45(2) $614-5$.

75. Toleman MA, Rolston K, Jones RN, Walsh TR. blaVIM-7, an evolutionarily distinct metallo-beta-lactamase gene in a Pseudomonas aeruginosa isolate from the United States. Antimicrob Agents Chemother. 2004;48(1):329-32.

76. Demiraslan H, Sevim M, Pala Ç, et al. Risk factors influencing mortality related to Stenotrophomonas maltophilia infection in hematology-oncology patients. Int J Hematol. 2013;97(3):414-20.

77. Safdar A, Rolston KV. Stenotrophomonas maltophilia: changing spectrum of a serious bacterial pathogen in patients with cancer. Clin Infect Dis. 2007;45(12):1602-9.

78. Al-Anazi KA, Al-Jasser AM. Infections caused by Stenotrophomonas maltophilia in recipients of hematopoietic stem cell transplantation. Front Oncol. 2014;4:232.

79. Brook I, Frazier EH. Aerobic and anaerobic infection associated with malignancy. Support Care Cancer. 1998;6(2):125-31.

80. Nesher L, Rolston KV. Neutropenic enterocolitis, a growing concern in the era of widespread use of aggressive chemotherapy. Clin Infect Dis. 2013;56(5):711-7.

81. Huang AM, Marini BL, Frame D, Aronoff DM, Nagel JL. Risk factors for recurrent Clostridium difficile infection in hematopoietic stem cell transplant recipients. Transpl Infect Dis. 2014;16(5):744-50.

82. Willems L, Porcher R, Lafaurie M, et al. Clostridium difficile infection after allogeneic hematopoietic stem cell transplantation: incidence, risk factors, and outcome. Biol Blood Marrow Transplant 2012;18(8):1295-301.

83. Jain T, Croswell C, Urday-Cornejo V, et al. Clostridium difficile colonization in hematopoietic stem cell transplant recipients: a prospective study of the epidemiology and outcomes involving toxigenic and nontoxigenic strains. Biol Blood Marrow Transplant. 2016;22(1):157-63.

84. Kinnebrew MA, Lee YJ, Jenq RR, et al. Early Clostridium difficile infection during allogeneic hematopoietic stem cell transplantation. PLoS One. 2014;9(3):e90158.

85. Hachem R, Hanna H, Kontoyiannis D, Jiang Y, Raad I. The changing epidemiology of invasive candidiasis: Candida glabrata and Candida kruse $i$ as the leading causes of candidemia in hematologic malignancy. Cancer. 2008;112(11):2493-9.

86. Maschmeyer G. The changing epidemiology of invasive fungal infections: new threats. Int J Antimicrob Agents. 2006;27(Suppl 1):3-6.

87. Steinbach WJ, Marr KA, Anaissie EJ, et al. Clinical epidemiology of 960 patients with invasive aspergillosis from the PATH Alliance registry. J Infect. 2012;65(5):453-64.

88. Kontoyiannis DP, Wessel VC, Bodey GP, Rolston KV. Zygomycosis in the $1990 \mathrm{~s}$ in a tertiary-care cancer center. Clin Infect Dis. 2000;30(6):851-6.

89. Marty FM, Cosimi LA, Baden LR. Breakthrough zygomycosis after voriconazole treatment in recipients of hematopoietic stemcell transplants. N Engl J Med. 2004;350(9):950-2.

90. Kontoyiannis DP, Lionakis MS, Lewis RE, et al. Zygomycosis in a tertiary-care cancer center in the era of Aspergillus-active antifungal therapy: a case-control observational study of 27 recent cases. J Infect Dis. 2005;191(8):1350-60.
91. Pongas GN, Lewis RE, Samonis G, Kontoyiannis DP. Voriconazole-associated zygomycosis: a significant consequence of evolving antifungal prophylaxis and immunosuppression practices? Clin Microbiol Infect. 2009;15(Suppl 5):93-7.

92. Lewis RE, Cahyame-Zuniga L, Leventakos K, et al. Epidemiology and sites of involvement of invasive fungal infections in patients with haematological malignancies: a 20-year autopsy study. Mycoses. 2013;56(6):638-45.

93. Campo M, Lewis RE, Kontoyiannis DP. Invasive fusariosis in patients with hematologic malignancies at a cancer center: 19982009. J Infect. 2010;60(5):331-7.

94. Lamaris GA, Chamilos G, Lewis RE, Safdar A, Raad II, Kontoyiannis DP. Scedosporium infection in a tertiary care cancer center: a review of 25 cases from 1989-2006. Clin Infect Dis. 2006;43(12):1580-4.

95. Saral R, Ambinder RF, Burns WH, et al. Acyclovir prophylaxis against herpes simplex virus infection in patients with leukemia. A randomized, double-blind, placebo-controlled study. Ann Intern Med. 1983;99(6):773-6.

96. Saral R, Burns WH, Laskin OL, Santos GW, Lietman PS. Acyclovir prophylaxis of herpes-simplex-virus infections. N Engl J Med. 1981;305(2):63-7.

97. Yoshikawa T, Asano Y, Ihira M, et al. Human herpesvirus 6 viremia in bone marrow transplant recipients: clinical features and risk factors. J Infect Dis. 2002;185(7):847-53.

98. Zerr DM, Boeckh M, Delaney C, et al. HHV-6 reactivation and associated sequelae after hematopoietic cell transplantation. Biol Blood Marrow Transplant. 2012;18(11):1700-8.

99. Mori T, Kato J. Cytomegalovirus infection/disease after hematopoietic stem cell transplantation. Int J Hematol. 2010;91(4):588-95.

100. Cohen L, Yeshurun M, Shpilberg O, Ram R. Risk factors and prognostic scale for cytomegalovirus (CMV) infection in CMVseropositive patients after allogeneic hematopoietic cell transplantation. Transpl Infect Dis. 2015;17(4):510-7.

101. Campbell AP, Guthrie KA, Englund JA, et al. Clinical outcomes associated with respiratory virus detection before allogeneic hematopoietic stem cell transplant. Clin Infect Dis. 2015;61(2):192-202.

102. Tomblyn M, Chiller T, Einsele H, et al. Guidelines for preventing infectious complications among hematopoietic cell transplant recipients: a global perspective. Preface. Bone Marrow Transplant. 2009;44(8):453-5.

103. Hirsch HH, Martino R, Ward KN, Boeckh M, Einsele H, Ljungman P. Fourth European conference on infections in Leukaemia (ECIL4): guidelines for diagnosis and treatment of human respiratory syncytial virus, parainfluenza virus, metapneumovirus, rhinovirus, and coronavirus. Clin Infect Dis. 2013;56(2):258-66.

104. Hutspardol S, Essa M, Richardson S, et al. Significant transplantation-related mortality from respiratory virus infections within the first one hundred days in children after hematopoietic stem cell transplantation. Biol Blood Marrow Transplant. 2015;21(10):1802-7.

105. Renaud C, Xie H, Seo S, et al. Mortality rates of human metapneumovirus and respiratory syncytial virus lower respiratory tract infections in hematopoietic cell transplantation recipients. Biol Blood Marrow Transplant. 2013;19(8):1220-6.

106. Shah DP, Ghantoji SS, Mulanovich VE, Ariza-Heredia EJ, Chemaly RF. Management of respiratory viral infections in hematopoietic cell transplant recipients. Am J Blood Res. 2012;2(4):203-18.

107. Egli A, Bucher C, Dumoulin A, et al. Human metapneumovirus infection after allogeneic hematopoietic stem cell transplantation. Infection. 2012;40(6):677-84.

108. Hughes WT, Armstrong D, Bodey GP, et al. 2002 guidelines for the use of antimicrobial agents in neutropenic patients with cancer. Clin Infect Dis. 2002;34(6):730-51. 
109. Hughes WT, Armstrong D, Bodey GP, et al. 1997 guidelines for the use of antimicrobial agents in neutropenic patients with unexplained fever. Infectious Diseases Society of America. Clin Infect Dis. 1997;25(3):551-73.

110. Hughes WT, Armstrong D, Bodey GP, et al. From the Infectious Diseases Society of America. Guidelines for the use of antimicrobial agents in neutropenic patients with unexplained fever. J Infect Dis. 1990;161(3):381-96.

111. Flowers CR, Seidenfeld J, Bow EJ, et al. Antimicrobial prophylaxis and outpatient management of fever and neutropenia in adults treated for malignancy: American Society of Clinical Oncology clinical practice guideline. J Clin Oncol. 2013;31(6):794-810.

112. Weissinger F, Auner HW, Bertz H, et al. Antimicrobial therapy of febrile complications after high-dose chemotherapy and autologous hematopoietic stem cell transplantation - guidelines of the Infectious Diseases Working Party (AGIHO) of the German Society of Hematology and Oncology (DGHO). Ann Hematol. 2012;91(8):1161-74.

113. Krause R, Valentin T, Salzer H, et al. Which lumen is the source of catheter-related bloodstream infection in patients with multilumen central venous catheters? Infection. 2013;41(1):49-52.

114. Yolin-Raley DS, Dagogo-Jack I, Niell HB, et al. The utility of routine chest radiography in the initial evaluation of adult patients with febrile neutropenia patients undergoing HSCT. J Natl Compr Cancer Netw. 2015;13(2):184-9.

115. Klastersky J, Paesmans M, Rubenstein EB, et al. The multinational association for supportive care in cancer risk index: a multinational scoring system for identifying low-risk febrile neutropenic cancer patients. J Clin Oncol. 2000;18(16):3038-51.

116. Phillips B, Wade R, Stewart LA, Sutton AJ. Systematic review and meta-analysis of the discriminatory performance of risk prediction rules in febrile neutropaenic episodes in children and young people. Eur J Cancer. 2010;46(16):2950-64.

117. Santolaya ME, Alvarez AM, Avilés CL, et al. Prospective validation of a risk prediction model for severe sepsis in children with cancer and high-risk febrile neutropenia. Pediatr Infect Dis J. 2013;32(12):1318-23.

118. Kern WV, Marchetti O, Drgona L, et al. Oral antibiotics for fever in low-risk neutropenic patients with cancer: a double-blind, ran- domized, multicenter trial comparing single daily moxifloxacin with twice daily ciprofloxacin plus amoxicillin/clavulanic acid combination therapy - EORTC infectious diseases group trial XV. J Clin Oncol. 2013;31(9):1149-56.

119. Rolston KV, Frisbee-Hume SE, Patel S, Manzullo EF, Benjamin RS. Oral moxifloxacin for outpatient treatment of low-risk, febrile neutropenic patients. Support Care Cancer. 2010;18(1): 89-94.

120. Jaksic B, Martinelli G, Perez-Oteyza J, Hartman CS, Leonard LB, Tack KJ. Efficacy and safety of linezolid compared with vancomycin in a randomized, double-blind study of febrile neutropenic patients with cancer. Clin Infect Dis. 2006;42(5):597-607.

121. Lisboa LF, Miranda BG, Vieira MB, et al. Empiric use of linezolid in febrile hematology and hematopoietic stem cell transplantation patients colonized with vancomycin-resistant Enterococcus spp. Int J Infect Dis. 2015;33:171-6.

122. Scheetz MH, Knechtel SA, Malczynski M, Postelnick MJ, Qi C. Increasing incidence of linezolid-intermediate or -resistant, vancomycin-resistant Enterococcus faecium strains parallels increasing linezolid consumption. Antimicrob Agents Chemother. 2008;52(6):2256-9.

123. Dellit TH, Owens RC, McGowan JE, et al. Infectious Diseases Society of America and the Society for Healthcare Epidemiology of America guidelines for developing an institutional program to enhance antimicrobial stewardship. Clin Infect Dis. 2007;44(2):159-77.

124. Nesher L, Tverdek FP, Mahajan SN, Chemaly RF, Rolston $\mathrm{KV}$. Ertapenem usage in cancer patients with and without neutropenia: a report on 97 cases from a comprehensive cancer center. Infection. 2015;43(5):545-50.

125. Tverdek FP, Rolston KV, Chemaly RF. Antimicrobial stewardship in patients with cancer. Pharmacotherapy. 2012;32(8):722-34.

126. Cosgrove SE, Seo SK, Bolon MK, et al. Evaluation of postprescription review and feedback as a method of promoting rational antimicrobial use: a multicenter intervention. Infect Control Hosp Epidemiol. 2012;33(4):374-80.

127. Paskovaty A, Pflomm JM, Myke N, Seo SK. A multidisciplinary approach to antimicrobial stewardship: evolution into the $21 \mathrm{st}$ century. Int J Antimicrob Agents. 2005;25(1):1-10. 